\title{
Defining the sports medicine specialist in the United Kingdom: a Delphi study
}

\author{
B Thompson, D MacAuley, O McNally, S O'Neill
}

See end of article for authors' affiliations .....................

Correspondence to: B Thompson, Sports Medicine Clinic Craigavon Area Hospital Portadown BT63 5QQ, Northern Ireland, UK; BThomp6605@aol.com

Accepted 28 April 2003

\begin{abstract}
Objective: To define the role and responsibilities of the sports medicine specialist using a recognised research technique.

Methods: A Delphi technique was employed using anonymous postal questionnaires sent to a random sample of 300 members of the British Association of Sport and Exercise Medicine. The questionnaire of 300 putative attributes was developed in a pilot study and the Delphi technique used allowed participants to modify their responses according to the responses of other participants.

Results: There was a $53 \%$ response to both rounds of the study with $75.6 \%$ of the respondents being male, $39 \%$ having a higher qualification in sports medicine, and $45.6 \%$ being general practitioners. Some $86.3 \%$ strongly agreed that sport and exercise medicine should be a recognised speciality and $90 \%$ strongly agreed that it should be available on the National Health Service (NHS). The most important specialist attributes were orthopaedic and soft tissue medicine ( $83.6 \%$ strongly agreed) and emergency medical management $(79.7 \%$ strongly agreed). More than $75 \%$ of respondents did not agree that either research or personal playing experience were relevant.

Conclusion: Sports and exercise medicine is an evolving speciality in the United Kingdom. We believe this is the first systematic attempt to define the role and responsibilities of the sports medicine specialist and the findings are of relevance to the future development of a career pathway.
\end{abstract}

S ports medicine is a well recognised speciality in many countries, but the nature of the speciality may differ. Sports medicine specialists may also be family doctors, general physicians, cardiologists, orthopaedic physicians or surgeons, rheumatologists, or specialists in public health medicine amongst other things. Each may be a specialist in sports medicine, but with very different knowledge and skills, viewing sport from many different personal or professional angles. They may care for the elite athlete, the top national teams and individual Olympians, or the everyday recreational athlete and each may have a different, yet legitimate, understanding of sports medicine.

So, what is a sports medicine specialist? The aim of the study was to explore the role and responsibilities of the sports medicine specialist. We attempted to define the sports medicine specialist from the UK perspective by asking those who have registered their interest in this field through membership of the British Association of Sport and Exercise Medicine. The specific objectives were to identify those attributes of training and expertise considered, by a national representative sample, to be most important in the sports medicine specialist. As there is no consensus in the United Kingdom on what constitutes a sports medicine specialist, there cannot be a defined training programme or career pathway.

Curriculum development has, to date, been defined by the examinations body behind each of the various qualifications. The curriculum for sports medicine training or examination has been defined in several countries including Canada, ${ }^{1}$ the Republic of Ireland, ${ }^{2}$ Germany, ${ }^{3}$ Finland, ${ }^{4}$ Australia, ${ }^{56}$ and America. ${ }^{78}$ All of these face the conundrum of defining the training programme to become a specialist when the attributes of that specialist are unknown.

We tried to identify other attempts to define the specialist from a literature search using the key words "sports medicine", "specialist", "training", and "qualities" but could identify no previous studies to help define the role or attributes of the sports medicine specialist. An editorial from The Physician and Sportsmedicine describes their attempts to define sports medicine which resulted in the statement that "sports medicine is practised in a number of venues by clinicians with overlapping but distinct areas of expertise".

\section{METHOD}

This study used the Delphi technique, a recognised research method of canvassing opinions using peer feedback. The Delphi technique is based on subjective consensus and according to Goodman "its purpose is to generate discussion and enable a judgement on a specified topic to be made so that policy decisions can be taken which can claim to represent a given group's wants and views". We sought the views of members of the British Association of Sport and Exercise Medicine (BASEM), a multidisciplinary speciality grouping of approximately 800 members. The diversity of background and professional experience of the members of BASEM allied to the commitment shown by membership was felt to present the best population from which to canvas opinion. The sample size was calculated to make the sample representative as a whole and the subgroups relatively small.

This technique is a well recognised method of obtaining consensus and has been used in many similar studies. ${ }^{10-31}$ In a preliminary study, we asked 13 sports medicine specialists with recognised higher qualifications in sports medicine (from backgrounds of orthopaedic surgery, general practice, and A\&E) in Northern Ireland to identify all those qualities they considered important for a sports medicine specialist. ${ }^{32}$

We identified the 300 putative attributes of the sports medicine specialist and used this list of qualities as the template for this national study. The list of attributes used in this study was identical to that determined by the pilot study and was categorised in 11 groups (table 1). One of these groups, as suggested in the pilot study, contained a list of principles of health care for sports medicine from the World Medical Association declaration amended in Budapest 1993.

Abbreviations: BASEM, British Association of Sport and Exercise Medicine; NHS, National Health Service 


\section{Table 1 Categories of attributes}

(1) Access availability and administration

(2) Clinical skills

(3) Education, teaching, and research

(4) Teamwork

(5) Uses of resources and investigations

(6) Ethics

(7) Communication skills

(8) Application of knowledge

(9) Treatment modalities

(10) Self management skills

(11) Practical skills

The entire list of statements was circulated to a computer generated random sample of 300 members of BASEM, using a mailing list supplied by the association, and each participant was invited to indicate how important they considered each attribute from "strongly agree", "agree", "neither", "disagree" to "strongly disagree". In the second round of the Delphi process we circulated a further copy of this list to all respondents and indicated the most frequent answer and the percentage of respondents who supported this answer. Participants were invited to score their level of agreement with each statement again, using the same criteria, but were permitted to change their views from their previous scores. This is a well recognised means of identifying opinions by consensus. Responses were collated and analysed using SPSS software with numerical values allocated to each response $(1=$ strongly disagree to $5=$ strongly agree $)$.

\section{RESULTS}

There were 160 (53\%) completed returns for both the first and second rounds. Of these, there were 121 male and 38 female respondents, composed of 73 general practitioners, 33 hospital specialists, six junior hospital doctors, 31 physiotherapists, and 14 other members including five sports scientists. Of these, 63 respondents had either a diploma (41) or masters degree ${ }^{22}$ in sports medicine. A total of 13 were currently studying for a qualification and one respondent had both qualifications.

The majority of respondents $(138 ; 86.3 \%)$ considered that sport and exercise medicine should be recognised as a speciality and 144 (90\%) considered that sports and exercise medicine should be available on the National Health Service (NHS). Most respondents $(105 ; 65.6 \%)$ considered that there should be higher specialist training. Of particular interest currently is the fact that $54(33.8 \%)$ believed that the Royal College of General Practitioners was the most appropriate mother college while $26(16.3 \%)$ believed it should be the Royal College of Surgeons and $33(20.6 \%)$ believed that the Royal College of Physicians would be most appropriate. Of the $34(21.3 \%)$ who considered that another body should have responsibility, $10(6.3 \%)$ specified a combined group of Royal Colleges and five $(3.1 \%)$ stated that it should be a specialist body or College of Sports Medicine.

Table 2 shows the scores for the top 20 attributes on the second round. This table includes only those statements with which more than $80 \%$ strongly agreed and prioritises what people consider to be the most appropriate attributes. In table 3 we show those statements where more than $25 \%$ of respondents disagreed or had a neutral opinion on their importance.

\section{DISCUSSION}

This study attempted to define the key attributes of training and expertise considered to be important in a sports medicine specialist. It is the largest and most representative study of the opinions of those with an interest in sports medicine reported in the literature. The strength of this study is that it provides consensus from the group as a whole and distances it from arguments between different factions, although it could be said that the role of the specialist should not be defined by generalists. It helps create a picture of what attributes are believed to be most important and it is of considerable value at a time when sport and exercise medicine is developing as a speciality in many countries, including the UK. This study uses a formal research technique to paint the picture, but future debate and discussion may help add colour and substance to this evolving outline.

As expected, the majority of respondents believe that sports and exercise medicine should be recognised as a speciality, and that sports and exercise medicine should be available on the NHS. After all, the sample base for this study was representative of the membership of the only multidisciplinary national organisation in the UK, and respondents were likely to be a self selected group of those with a particular interest. What is, perhaps, more interesting is that $15.7 \%$ did not feel that sports medicine should be a separate speciality and that $10 \%$ did not believe that it should be funded by the NHS. Even in this group, who believe strongly in the importance of the speciality, just under two thirds considered that there should be higher specialist training. Once again, the majority vote was not unexpected, but the surprising finding was that one third did not consider higher specialist training necessary. There is, therefore, even in this selected sample, a considerable group who regard sports medicine as a special interest, rather than as an independent career.

Opinions varied on which college should take overall responsibility for development of the sports medicine specialist with one third in favour of the Royal College of General Practitioners, one fifth in favour of the Royal College of Physicians, and one sixth suggesting the Royal College of Surgeons. This is interesting in the context of developments in the Republic of Ireland, where the Royal Colleges of Physicians and of Surgeons have recently joined to support a new Faculty of Sport and Exercise Medicine.

The prime aim of the study was to identify those attributes that were considered most important for a sports medicine specialist. The list of qualities with which more than $80 \%$ of respondents strongly agreed included both generic and specific skills and there was no statement with which every respondent strongly agreed. Of the 22 statements, 12 were general statements relating to appropriate care that could be applied to any medical professional, irrespective of their speciality. Ten statements could be regarded as having special relevance to sport and exercise medicine and can help define the parameters of the discipline.

It was interesting to note the emphasis on emergency care and, in particular, on the management and transfer of the acutely injured patient. Two of the top 22 attributes related to access and referral to physiotherapy colleagues, underlining the importance of multidisciplinary sports medicine care. We also tried to quantify the importance of the contributions of the various specialities (table 4). Orthopaedic medicine and soft tissue care was ranked as most important, followed by the assessment and management of emergencies in the field, and a working knowledge of rehabilitation, including physiotherapy.

The attributes that scored highest were those relating to medical indemnity and remaining sober while on duty, and nine of every ten respondents believed these were very important. One may, of course, wonder why $10 \%$ of respondents did not strongly agree, but overall all respondents agreed with the statement.

Each of the statements included in the study had been considered important by at least one of the original panel in the pilot study. Yet, there were a number of statements with 
Table 2 Proportion of respondents who strongly agreed with the statement

\begin{tabular}{ll}
\hline The statement & Strongly agree, \% \\
\hline Has appropriate medical indemnity & 90.6 \\
Remains sober while on duty & 88.9 \\
When the sports participant is a professional sportsman or athlete and derives livelihood & 88.1 \\
from that activity the physician should pay due regard to the occupational aspects involved & \\
Knowledge and understanding of how injury affects sport & 87.5 \\
Provides immediate/early access for acutely injured athletes & 87.4 \\
Ability to formulate appropriate management plan based on history and examination & 85.8 \\
Monetary gain should not influence clinical decisions & 85.8 \\
Avoid negligence & 85 \\
Ability to formulate accurate differential diagnosis from full history and examination & 84.4 \\
Should be competent at CPR/basic life support & 84.4 \\
Have personal and professional integrity & 84.3 \\
Deals competently with mistakes & 84.1 \\
Does not endanger patient's health nor causes needless suffering & 83.7 \\
Should be competent at cervical spine immobilisation and protection & 83.6 \\
Knowledge and understanding of soft tissue injury/orthopaedic medicine & 83.6 \\
Can ensure an injured athlete is transferred safely in emergency situation & 83.6 \\
Ability to perform detailed, systematic, general, and sports related history & 83.6 \\
Has access to physiotherapist & 83.5 \\
Appropriate referral to physiotherapy and liaison in management & 82 \\
Refers appropriately & 81.1 \\
In sports medicine as in all other branches of medicine professional confidentiality must be & 81.0 \\
observed. The right to privacy over medical attention the sportsman/athlete has received & \\
must be protected, especially in the case of professional sportsmen/athletes & \\
Updates and maintains clinical skills & 80.5 \\
\hline
\end{tabular}

which few agreed nationally. This helps us to identify those areas that respondents would not prioritise. Of the top ten statements with which more than $25 \%$ of respondents would disagree or were neutral, five were related to research and publication. Clearly these academic endeavours are not considered important, although recent opinions suggest that they are important. ${ }^{33}$ In fact an article on post-graduate medical education with regard to sports medicine stated that "it is generally agreed that an understanding of the principles of research and the ability to assess critically the results of published work are essential attributes of a doctor" ${ }^{34}$ This is in keeping with the British Medical Association statement that "an individual with expertise in sport and exercise medicine will understand the need for continuing research and audit". ${ }^{35}$ More surprising, perhaps, was that three quarters did not consider it important that sports medicine specialists should have experience as a player, nor that they should have a formal attachment to a team.

There have been few attempts in other disciplines to define a speciality or curriculum using a formal method. In one study of 730 medical graduates, researchers tried to prioritise areas of knowledge in order to define a curriculum and the educational objectives of a surgical curriculum using a Delphi study. ${ }^{36}$ Similarly, a smaller study of 21 general practitioners aimed to find consensus on competencies required in a postgraduate therapeutics course. ${ }^{37}$ These studies were

Table 3 Attributes with which more than $25 \%$ would disagree or remain neutral

\begin{tabular}{ll}
\hline The statement & Disagree or neutral, \% \\
\hline Has relevant publications and aspires to a research qualification & 80.5 \\
Experience as a player at different levels & 75.5 \\
Can write a research paper & 71.6 \\
Supervises relevant research by other doctors (A\&E, GPs) & 67.9 \\
Speaks well to the media & 66.1 \\
Can write an educational paper & 66.1 \\
Has combined clinics with orthopaedics/rheumatology & 65.9 \\
Lectures well & 62.3 \\
Has a formal attachment to a team or sport & 62.2 \\
Up to date on current diving legislation & 61.5 \\
Ability to formulate business plan for sports injury clinic & 60.4 \\
Provide phone coverage & 58.7 \\
Competent in manipulative and mobilisation techniques & 56.8 \\
Provides information leaflets & 38.7 \\
Initiates and completes research relevant to sport and exercise medicine & 36.8 \\
Involved and local and national bodies & 36.5 \\
Uses sports medicine skills in a mainstream medical/surgical post & 35.4 \\
Always available to help others & 33.9 \\
Experience in general practice & 33.6 \\
Ability to strap/tape & 32.0 \\
Has access to pain clinic & 31.0 \\
Attends training sessions and games frequently & 30.1 \\
Prepared to cover the absence of others & 27.6 \\
Familiar with all aspects of a wide range of sports at various levels & 26.8 \\
Should have experience of working as team doctor to a variety of sports both team & 26.7 \\
and individual & \\
Helps with physiotherapy/podiatry training & 25.8 \\
\hline
\end{tabular}


Table 4 The importance of different specialist attributes

\begin{tabular}{ll}
\hline The statement & Strongly agree, \% \\
\hline Orthopaedic medicine/soft tissue & 83.6 \\
Should be competent in the assessment and management of emergencies in the field & 79.7 \\
Working knowledge of rehabilitation, especially physiotherapy & 72.7 \\
Sports related asthma & 30.5 \\
Pharmacology and prescribing & 28.9 \\
Physiology & 25.8 \\
Knowledge and understanding of: general medicine & 21.9 \\
Rheumatology & 16.4 \\
Psychology & 16.4 \\
Cardiology & 10.9 \\
ENT & 7.8 \\
Gynaecology & 7.0 \\
\hline
\end{tabular}

\section{Take home message}

There is still lack of agreement in the UK as to the precise nature of the key attributes of a sports medicine specialist. Until there is agreement on this there cannot be a suitable training scheme.

successful in reaching consensus among professionals, but we could identify no formal research on sports medicine. An expert panel, convened from ten specialists in sport and exercise medicine in the United States, ${ }^{38}$ issued a consensus statement in order to provide guidelines on what would be expected from a team physician (as opposed to a sports medicine specialist). They identified the definition, qualifications, duties, and education of a team physician, but it was not undertaken using a formal research based consensus method. In our study, we used a recognised method to identify the opinions of those who had signalled their interest in the field through their membership of BASEM and we believe that this is the first systematic attempt to define the roles and responsibilities of the sports medicine specialist.

\section{ACKNOWLEDGEMENTS}

We would like to thank all those who participated in both the pilot and main studies for their patience and diligence in completing the lengthy questionnaires.

\section{Authors' affiliations}

B Thompson, Sports Medicine Clinic, Craigavon Area Hospital, Portadown BT63 5QQ, Northern Ireland, UK

D MacAuley, Department of Epidemiology and Public Health, The Queen's University of Belfast, Belfast BT12 6BJ, Northern Ireland, UK O McNally, S O'Neill, Institute of Postgraduate Medical and Health Sciences, University of Ulster, Newtownabbey BT37 OQB, Northern Ireland, UK

Conflict of interest: none declared.

\section{REFERENCES}

1 Taunton JE. Fellowship in Sports Medicine. Br J Sports Med 2000;34(4):238.

2 O'Brien M, Mahoney $N$. The role of a masters degree as part of higher training in sports and exercise medicine or why do a masters? Br J Sports Med 2000;34(4):237-8

3 Beneke R. The German situation. Br J Sports Med 2000;34(4):238-9.

4 Kannus P, Parkkari J. Sports and exercise medicine in Finland. Br J Sports Med 2000;34(4):239-40.

5 Fricker P. Sports medicine education in Australia. Br J Sports Med 2000;34(4):240-1.

6 Australian College of Sports Physicians. A manual for candidates. 4th ed. Crows Nest, NSW 2065, Australia: Australian College of Sports Physicians, 1995.

7 American Academy of Family Physicians. Recommended curriculum guidelines for family practice residents - sports and recreational medicine. Shawnee Mission, KS: American Academy of Family Physicians, 1984 (rev 1995).

8 Curl WW, Bomberger IE. Sports medicine training in the United States. Br J Sport Med 2001;35:362.
9 Matheson GO. Sports medicine: a focus on health. Phys Sportsmed 1999;27(10):7.

10 Goodman CM. The Delphi technique: a critique. J Adv Nurs 1987; 12:729-34.

11 Stewart J, O'Halloran C, Harrigan P, et al. Identifying appropriate tasks for the preregistration year: a modified Delphi technique. BMJ 1999;19:224-9.

12 Baldwin PJ, Paisley AM, Paterson Brown S. Consultant surgeons' opinion of the skills required of basic surgical trainees. Br J Surg 1999;86:1078-82.

13 Williams PL, Webb C. The Delphi technique: a methodological discussion. J Adv Nurs 1994; 19:180-6.

14 Everett A. Piercing the veil of the future. A review of the Delphi method of research. Prof Nurse 1993;9(3):181-5.

15 Crisp J, Pelletier D, Duffield C. It's all in a name. When is a "Delphi study" not a Delphi study? Aust J Adv Nurs 1999;16(3):32-7.

16 Hollis N, Davis I, Reeb R. Use of a Delphi technique to prioritize clinical nursing research needs. NursingConnections 1995;8(4):65-70.

17 Jairath N, Weinstein J. The Delphi methodology (part one): a usefu administrative approach. Can J Nurs Admin 1994;7(3):29-42.

18 Duffield C. The Delphi technique. Aust J Adv Nurs 1988;6(2):41-4.

19 Gibson JME. Using the Delphi technique to identify the content and context of nurses' continuing professional development needs. J Clin Nurs 1998;7:451-9.

20 Campbell SM, Roland MO, Quayle JA, et al. Quality indicators for general practice: which ones can general practitioners and health authority managers agree are important and how useful are they? J Public Health Med 1998:20(4):414-21.

21 McKenna HP. The Delphi technique: a worthwhile research approach for nursing? J Adv Nurs 1994; 19:1221-5.

22 Holden J, Wearne J. Membership by assessment of performance: developing a method for assessing established general practitioners. $\mathrm{Br} J$ Gen Pract 2000;50:231-5

23 Green B, Jones $M$, Hughes D, et al. Applying the Delphi technique in a study of GPs' information requirements. Health Soc Care Commun 1999:7(3):198-205

24 Hasson F, Keeney S, McKenna H. Research guidelines for the Delphi survey technique. J Adv Nurs 2000;32(4):1008-15.

25 Keeney S, Hasson F, McKenna H. A critical review of the Delphi technique as a research methodology for nursing. Int J Nurs Stud 2001;38(2):195-200.

26 Verhagen AP, de Vet HC. The Delphi list: a criteria list for quality assessment of randomized clinical trials for conducting systematic reviews developed by Delphi consensus. J Clin Epidemiol 1998;51(12):1235-41.

27 Barker K, Burns M. Using consensus techniques to produce clinical guidelines for patients treated with the llizarov fixator. Physiotherapy $2001 ; 87(6): 289-96$.

28 Cross V. Approaching consensus in clinical competence assessment. Physiotherapy 2001;87(7):341-50.

29 Cantrill JA, Sibbald B, Buetow S. The Delphi and nominal group techniques in health services research. Int J Pharm Pract 1996;4:67-74.

30 Campbell SM, Cantrill JA, Roberts D. Prescribing indicators for UK general practice: Delphi consultation study. BMJ 2000;321:425-8.

31 Munro N, Hornung R, McAleer S. What are the key attributes of a good general practice trainer: a Delphi study. Educ Gen Pract 1998;9:263-70.

32 Thompson B, McNally O, $\mathrm{O}^{\prime}$ Neil S, et al. What is a sports medicine specialist: a pilot study. Br J Sports Med 2000;34(4):243-4.

33 McCrory P. Research realpolitik. Br J Sports Med 2002;36(1):1

34 Long G, Gibbon WW. Br J Sports Med 2000;34(4):236-7.

35 British Medical Association Board of Science and Education. Sport and exercise medicine: policy and provision. London: British Medical Association, 1996.

36 Lawrence PF, Alexander RH, Bell RM, et al. Determining the content of a surgical curriculum. Surgery 1983;94(2):309-17.

37 Boath E, Mucklow J, Black P. Consulting the oracle: a Delphi study to determine the content of a postgraduate distance learning course in therapeutics. Br J Clin Pharmacol 1997;43(6):643-7.

38 Herring SA, Bergfield JA, Boyd J, et al. Team Physician Consensus Statement Am J Sports Med 2000;28:440-2. 